Volume 2, Nomor 1, September 2021, hlm 66-75

BEMAS: JURNAL BERMASYARAKAT

p ISSN 27455866 | e ISSN 27457958

\title{
Pendampingan Pembelajaran Keterampilan Secara Daring di Pondok Pesantren Tarbiyatul Iman Malang
}

\author{
Achmad Fauzan Hery Soegiharto ${ }^{1 *}$, Sudarman*
}

Program Studi Teknik Mesin, Universitas Muhammadiyah Malang, Malang, Jawa Timur, Indonesia 6541

Email: ${ }^{1 * a c h m a d f a u z a n @ u m m . a c . i d, ~ * s u d a r m a n @ u m m . a c . i d ~}$

\author{
INFORMASI ARTIKEL \\ Article History: \\ Submission: 02-09-2021 \\ Revised: 23-09-2021 \\ Accepted: 26-09-2021 \\ * Korespondensi: \\ Achmad Fauzan Hery \\ Soegiharto \\ achmadfauzan@umm.ac.id
}

\begin{abstract}
ABSTRAK
Pengabdian pada masyarakat ini bermitra dengan Pondok Pesantren Tarbiyatul Iman (PPTI), Malang. Pondok mengalami kesulitan penyelenggaraan pembelajaran praktek memasak, pada kondisi pandemi. Pengajar tidak diperkenankan bertemu tatap muka langsung di kelas. Sedangkan pelajaran praktek membutuhkan pengamatan, pembimbingan secara langsung pada saat pelaksanaan. Tujuan pengabdian pada masyarakat ini adalah mendapatkan solusi pembelajaran keterampilan memasak yang terkendala akibat pandemi covid-19. Metodenya adalah pengajar (pengajar) mengajar secara daring, sedang santri berada di kelas praktek bersama. Video tutorial memasak, yang dibuat pengajar di share lebih dulu kepada santri 3 hari sebelum pelajaran. Pengajar mengajar secara online, di ruang guru, menggunakan laptop, dan peralatan bantu extended monitor, microphone smartphone, sound power. Di ruang kelas praktek disediakan laptop untuk komunikasi dengan pengajar, dan juga dilengkapi IP camera yang terhubung dengan laptop/ smartphone pengajar. IP camera dapat dikendalikan menghadapnya sehingga seakan akan pengajar ada di kelas. Masakan yang dicobakan salah satunya adalah makanan yang disukai pada umumnya remaja, dalam hal ini dipilih mie Jepang. Bumbu dan topping semaksimalnya disesuaikan dengan resep aslinya, yang didapatkan di pasar lokal. Masakan dipresentasikan/ disajikan dalam wadah ala restoran. Evaluasi hasil memasak melibatkan pengajar/ ustad lain. Santri dapat mengikuti kegiatan ini dengan baik, mengikuti dengan gembira, dipandu dengan baik, aktifitas santri terpantau dengan baik, dan hasil masak yang memuaskan. Pengajar dapat melaksanakan pembelajaran kelas secara daring-luring, lebih terampil menguasai berbagai peralatan, lebih mudah dalam memantau kelas, dan mudah dalam mengevaluasi. Kegiatan ini berhasil dilaksanakan dengan baik dan dapat dijadikan raw model pembelajaran praktek secara daring-luring. Aman mengikuti protokol pencegahan covid 19.

Kata kunci: Praktek, Memasak, Luring, Daring, Pesantren.

Online Skills Learning Assistance at Pondok Pesantren Tarbiyatul Iman Malang

\begin{tabular}{l} 
ABSTRACT \\
\hline This community service partnered with Tarbiyatul Iman Islamic Boarding \\
School (PPTI), Malang. The purpose of this community service is to have a \\
solution for cooking skills learning that are constrained by the COVID-19 \\
pandemic. The method is Pengajar teaching online, while students are in \\
class practice together. The cooking tutorial video, which was made by the \\
pengajar, was shared with the students 3 days before the lesson. Pengajar \\
teaches online, in the teacher's room, using a laptop, and extended \\
monitors, smartphone microphones, sound power. In the practice
\end{tabular}
\end{abstract}




\begin{abstract}
classroom, a laptop is provided for communication with the pengajar, and is also equipped with an IP camera that is connected to the pengajar's laptop/smartphone. The IP camera can be controlled facing it so that it seems as if the pengajar is in class. The dishes that are tried are foods that are generally liked by teenagers, in this case Japanese noodles are chosen. Seasonings and toppings are adjusted to the maximum extent of the original recipe, which is obtained at the local market. Food is presented / served in a restaurant-style. Evaluation of cooking results involving other ustadz/ pengajar. Satri can participate in this activity well, happily participates, is well guided, students' activities are well monitored, and the cooking results are satisfactory. Pengajar can carry out classroom learning online, are more skilled at mastering various equipment, are easier to monitor classes, and are easier to evaluate. This activity was successfully implemented and can be used as a raw model for online practical learning. It's safe to follow the covid 19 prevention protocol.
\end{abstract}

Keywords: Practice, Cooking, Offline, Online, Boarding school.

\title{
1. PENDAHULUAN
}

Pandemi covid-19 telah membawa dampak dalam sektor ekonomi dan sosial. Perusahaan melakukan perubahan dengan menerapkan system bekerja dari rumah atau yang dikenal dengan Work from Home (WFH). Dunia pendidikan juga mengalami penyesuaian. Semua level pendidikan melaksanakan pola pendidikan secara daring (Dalam Jaringan).

Pondok Pesantren Tarbiyatul Iman atau PPTI, berada di Perumahan Srigading Dalam, RT/RW 03/02 Kel Jatimulyo, Kec. Lowokwaru, Malang. Lokasi berdekatan dengan universitas terkemuka di Malang seperti: Universitas Brawijaya $( \pm 1,5 \mathrm{~km})$, Universitas Negeri Malang $( \pm 4 \mathrm{~km})$, Universitas Muhammadiyah Malang $( \pm 4 \mathrm{~km})$, Universitas Islam Negeri Malang $( \pm 4 \mathrm{~km})$ dan Universitas Widyagama $( \pm 3 \mathrm{~km})$, yang merupakan pusat pendidikan tinggi di Malang. Merupakan Pondok Pesantren di bawah Lembaga Pendidikan PUTERA ZAMAN (LPPZ), yang berorientasi kepada pendidikan berkelanjutan yang menggabungkan konsep integrasi keilmuan umum dengan basis agama. Dalam bidang dakwah verbal, LPPZ ini juga bergerak di tengah masyarakat dengan memberikan bekal pelatihan yang sistematis dan komprehensif kepada para pendakwah agar penyebarannya merata dan dapat diterima, sehingga syiar Islam dapat dirasakan masyarakat secara luas [1]. Selama pandemi covid-19, Pondok mengalami kesulitan penyelenggaraan pembelajaran praktek memasak, pada kondisi pandemi. Pengajar tidak diperkenankan bertemu tatap muka langsung di kelas. Sedangkan pelajaran praktek membutuhkan pengamatan, pembimbingan secara langsung pada saat pelaksanaan.

Program pendidikan di Pondok Pesantren Tarbiyatul Iman dilaksanakan secara terpadu dalam kurikulum pendidikan umum (MTs) yang membekali santri dengan ilmu umum dan pendidikan pesantren yang mendalami agama (tafaqquh fiddin) selama 24 jam non-stop. Pada masa darurat pandemi covid, para santri telah diperlakukan sesuai protokol pencegahan penyebaran covid-19, yaitu dengan kedatangan bertahap melalui karantina. Pondok menjadi karantina besar, bagi sivitasnya, para santri di dalam pondok seperti keluarga di dalam rumah. Interaksi keluar masuk pondok amat sangat dibatasi. Para ustadz dan pengajar yang tinggal di pondok, diperkenankan mengajar tatap muka di kelas, dengan penerapan protokol kesehatan [2].

Pembelajaran dilaksanakan, di kelas. Bagi Ustadz/pengajar pengajar yang mukim di dalam pondok maka pembelajaran dilaksanakan secara tatap muka langsung. Permasalahan adalah bagi ustadz yang terpaksa harus beraktivitas di luar, maka dilarang keras masuk pondok. Pembelajaran mesti dilaksanakan di tempat terpisah antara ustadz dan santriwati. Cara yang dipilih adalah para santri 
Pendampingan Pembelajaran Ketrampilan Secara Daring di Pondok Pesantren

Tarbiyatul Iman Malang

berada dalam kelas, sedangkan ustadz/pengajar di ruang lain, atau di rumah. Pembelajaran cara ini memerlukan LCD/ monitor besar, atau TV agar para santri melihat ustad/pengajar pengajar[2].

Cara pembelajaran Ustad daring-santri luring dapat mudah dilaksanakan pada pembelajaran teori, pelajaran alquran, namun sulit untuk pelajaran berbasis praktek keterampilan, seperti menjahit, dan memasak. Pada kondisi normal, Pelajaran praktek memasak dilaksanakan di ruang kelas praktek, secara tatap muka. Teori, konsep, gagasan dibahas lebih dulu di kelas. Berikutnya sesuai jadwal dilaksanakan praktek memasak. Santriwati dibagi dalam 3 kelompok. Semua kelompok memasak hal yang sama. Peralatan memasak sudah disediakan, mulai dari kompor, talenan, pisau, mixser, blender, oven, dan keperluan lainnya. Pengajar mendampingi, mengarahkan agar dicapai hasil sebaik baiknya. Baik dari prosesnya, rasa dan penyajiannya. Hasil memasak dihidangkan di kantor ustad untuk diberikan penilaian[3]-[5].

Pada situasi pandemi, dimana akses pertemuan langsung pengajar sangat dibatasi, maka kelas luring, tatap muka praktek memasak harus diadaptasikan. Pengajar praktek memasak yang tidak mukim di pondok tidak diperkenankan tatap muka. Pondok menyediakan ruang khusus bagi pengajar secara online. Sementara santriwati di ruang kelas bersama. Kelas berlangsung secara luring-daring. Maka pembelajaran praktek memasak harus diadaptasikan supaya didapat kualitas output dan outcome pembelajaran yang baik. Permasalahannya adalah bagaimana cara pengelolaan, bagaimana teknis pelaksanaan, bagaimana pengelolaan kelas praktek, pilihan masakan agar siswa tertarik dan antusias sekalipun ustad/ pengajar tidak hadir di ruang kelas. Pengabdian pada masyarakat ini ditujukan untuk memperkuat adaptasi pembelajaran dari tatap muka kelas biasa menjadi kombinasi tatap muka-maya. Mulai dari penyampaian teori atau tutorial memasak, hingga praktek memasak dan penyajiannya. Solusi yang ditawarkan pada pengabdian pada masyarakat ini meliputi:

Pembelajaran praktek memasak daring luring; Pengajar menyiapkan materi pembelajaran sebelum pelaksanaan praktek memasak; Materi pembelajaran berupa tatap maya atau daring; Latihan atau pendampingan pelaksanaan daring, agar tidak terjadi gagap teknologi; Pembuatan video tutorial memasak; Setting peralatan; Pemasangan dan setting IP camera; Pelaksanaan praktek di kelas dengan pemantauan melalui IP camera dan komunikasi menggunakan laptop[4]. Target dan luaran pengabdian pada masyarakat ini adalah:

> Penguasaan teknologi dan perangkat untuk pembuatan tutorial memasak. Pengajar yang belum terbiasa menggunakan perangkat elektronik untuk pembelajaran praktek didampingi agar terampil menggunakan, dan bisa melaksanakan pembelajaran.

$>$ Pada pengabdian pada masyarakat ini diharapkan dihasilkan video tutorial memasak, dimana pengajar akan menjelaskan bagaimana persiapan memasak, cara memasak, secara ringkas jelas. Konten dari video ini adalah satu resep masakan dan cara pembuatannya. Akan dihasilkan beberapa video memasak.

$>$ Berfungsinya IP camera dalam pemantauan kelas, dimana IP camera terhubung ke laptop melalui wifi pondok, kemudian ke internet dan kemudian ke HP dan atau laptop pengajar.

Terlaksananya kelas praktek dimana santri bersama berada dalam kelas praktek. Sedangkan pengajar berada di ruang guru mengajar secara daring.

$>$ Keberhasilan pembelajaran memasak, dimana nilai yang dihasilkan dari kegiatan pengabdian ini minimal menghasilkan nilai yang sama dibandingkan nilai luring sebelum pandemi. $\mathrm{t}$ pandemi. Pembelajaran memasak.

\section{METODE PELAKSANAAN}

Pelaksanaan kegiatan pengabdian ini menggunakan metode konsultasi/pendampingan/mediasi. Pendampingan sejak pemilihan masakan atau jenis masakan, percobaan memasak, penyediaan fasilitas 
perekaman, video editing hingga menjadi video tutorial. Video tutorial diserahkan PPTI/ kantor untuk diteruskan kepada siswa/santriwati. Percobaan dan pendampingan menggunakan mesin mie hingga percobaan memasak mie Jepang. Para santriwati belajar mandiri menggunakan video tutorial. Pada kegiatan ini peserta pembelajaran praktek memasak adalah seluruh santriwati kelas 8 dimana dibagi dalam 3 kelompok memasak. Santriwati yang dipandang memiliki ketrampilan lebih dari temannya didistribusikan merata di kelompok, agara menjadi agen aktivasi teman temannya.

Pendampingan selanjutnya adalah pemasangan, dan setting IP camera di ruang kelas praktek, dan menghubungkannya dengan laptop, serta operasional IP camera. Pembelajaran praktek dilaksanakan di kelas[1], [4]-[6]. Pengajar mengajar secara online, di ruang guru, menggunakan laptop, dan peralatan bantu extended monitor, microphon smartphone, sound power. Di ruang kelas praktek disediakan laptop untuk komunikasi dengan pengajar, dan juga dilengkapi IP camera yang terhubung dengan laptop/ smartphone pengajar. Masakan yang dicobakan adalah makanan yang disukai pada umumnya remaja, dalam hal ini dipilih mie Jepang. Bumbu dan topping semaksimalnya disesuaikan dengan resep aslinya, yang didapatkan di pasar lokal. Masakan dipresentasikan/ disajikan dalam wadah ala restoran. Evaluasi hasil memasak melibatkan pengajar/ustadz lain[3][4].

Persiapan alat meliputi : Dua buah lampu sorot, untuk penerangan terfokus. Masing masing 10 watt. ; Stand HP; Alas sajian masak; Alas masak,; Microphone condenser; Stand microphone; 48V power sound; Laptop, Extended monitor; IP camera EZVIZ.

\section{HASIL DAN PEMBAHASAN}

Pelaksanaan percobaan mesin mie. Pada percobaan ini langsung digunakan untuk adonan mie sesungguhnya, yaitu mie pasta. Percobaan untuk mengetahui dan memastikan dan juga rekomendasi jika diperlukan memodifikasi mesin, atas saran pengguna (pengajar pondok)[7].

Terdapat proses pengadukan adonan, yaitu adonan tepung terigu cakra, dimana mengandung gluten tinggi 500 gr, telur 2, tepung kanji 100 , garam 1 sdt, air 80ml hingga $100 \mathrm{ml}$, minyak goreng. Pada pembuatan mie praktek, jumlah adonan disesuaikan dengan kebutuhan praktek santri di Pondok.
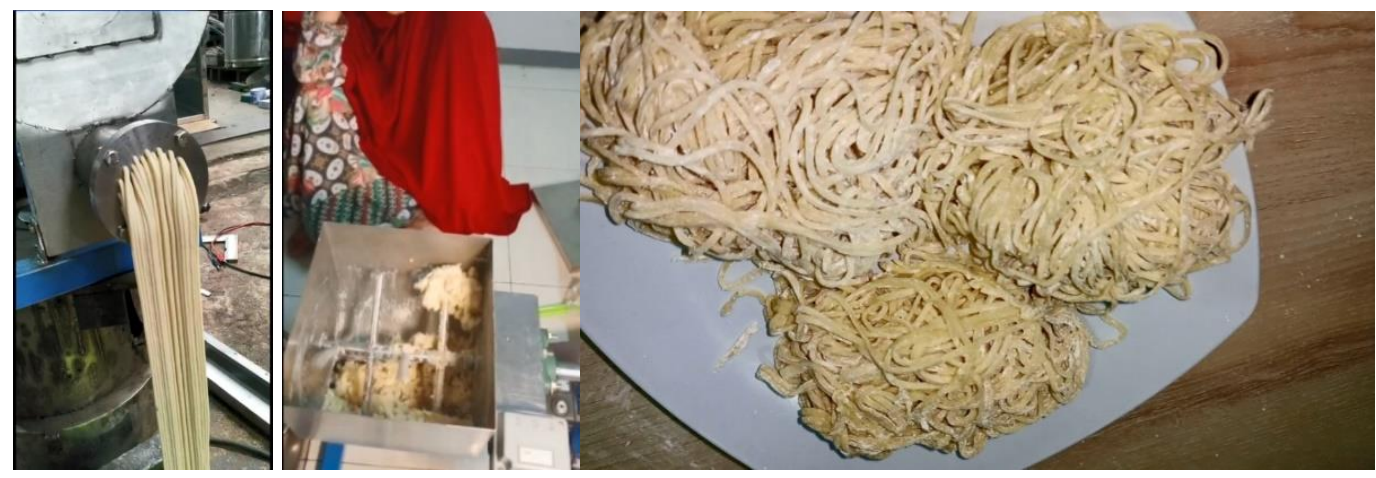

Gambar 1. Percobaan mesin mie

Percobaan oleh pengajar, adalah untuk membiasakan pengajar engan mesin tersebut. Disamping itu untuk mencoba, dan mendapatkan masukan tentang mesin tersebut. Agar mesin tersebut dapat disempurnakan sesuai kebutuhan, saran dan masukan. Percobaan ini untuk mengetahui pola aliran keluar extruder. Sehingga dapat dikenali kualitas adonan, dan bagaimana karaktristik mie nya setelah melalui lubang pencetakan [8], [9]. Percobaan ini sekaligus untuk menjajaki kemungkinan modifikasi mesin menjadi mesin lain, agar menjadi multiguna. Mie yang sudah jadi, dikepalkan seukuran kepalan tangan, kira kira satu kepalan jika dimasak menjadi 1 porsi, masakan mie[7], [10], [11].

Memasak mie tidak hanya mie nya sendiri, namun juga toppingnya, atau hiasan, atau kudapan diatasnya. Hal ini penting agar masakan kelihatan menarik dan rasa menjadi lebih bercitarasa[10][14]. Sebelum pelaksanaan praktek memasak di pondok, dibuat lebih dahulu video tutorial 
Pendampingan Pembelajaran Ketrampilan Secara Daring di Pondok Pesantren

Tarbiyatul Iman Malang

pembelajaran, untuk ditonton para santri sebelum praktek. Pada saat praktek santri memasak dibawah pengawasan pengajar [4].

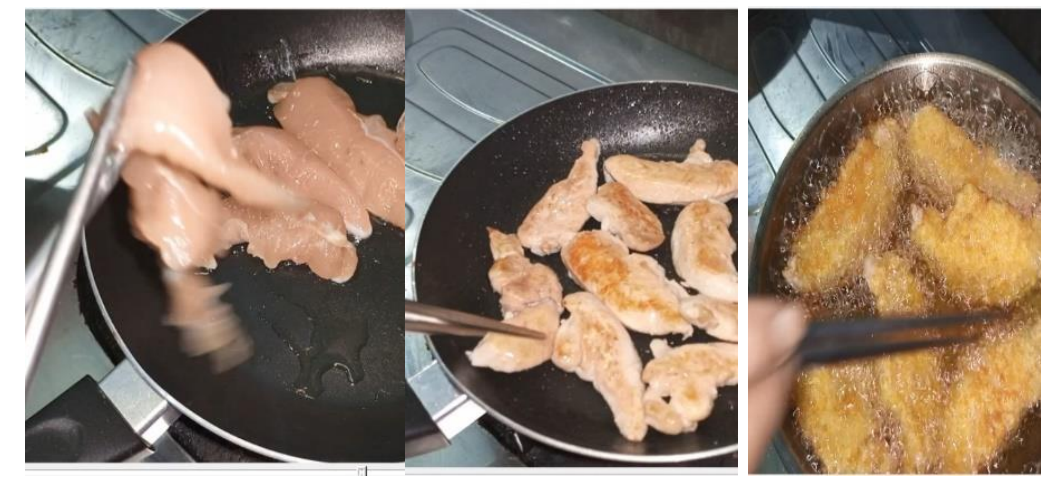

Gambar 3. Menggoreng untuk topping

Mie pasta yang dihasilkan hendak dibuat masakan bergaya Jepang. Diantara topping yang dibuat adalah potongan fillet ayam. Fillet ayam dipotong $2 \times 5 \mathrm{~cm}$, memanjang ketebalan, $1 \mathrm{~cm}$. Digoreng menggunakan mentega.

Setelah mempersiapkan topping untuk mie, maka selanjutnya adalah memasak mie. Tema yang dipilih adalah mie jepang. Begitupula topping yang sudah dibuat dan mie nya. Tema ini dipilih karena merupakan mie kekinian, yang disukai para remaja, dan para muda [11], [14]-[17].

Topping kedua adalah daging ayam fillet dengan bungkus tempura, dan bumbu penyedap jepang. Penggorengan digunakan adalah deep fryer. Dalam hal ini praktisnya adalah panci stainless tebal, dengan minyak diisi setengahnya.

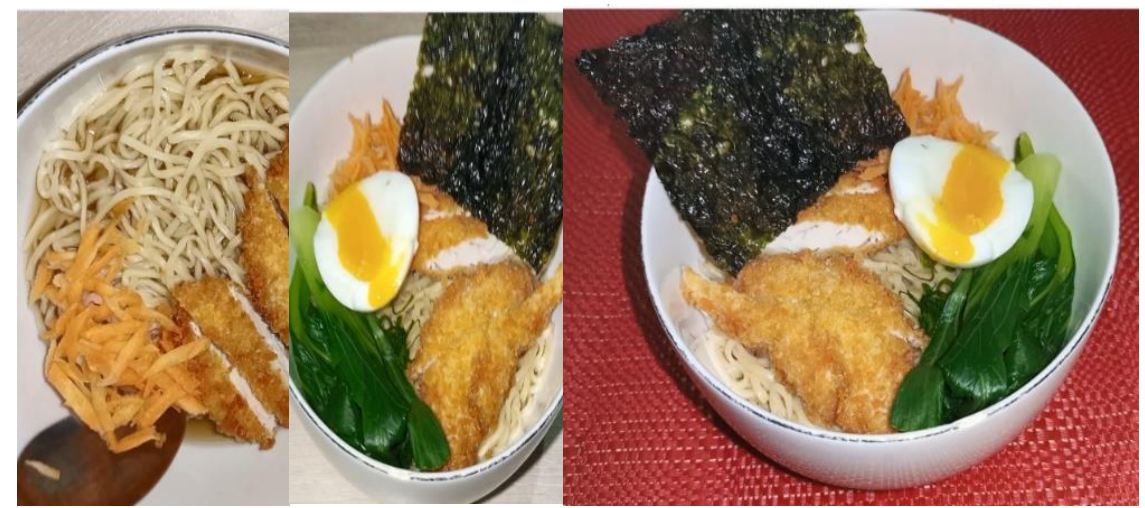

Gambar 4. Pemasakan mie

Selanjutnya adalah menyiapkan mie rebus. Mie direbus hingga matang, tiriskan dan diberi kuah Jepang yang telah disiapkan. Topping atau lauk berupa ayam fillet goreng dan fillet bungkus tempura, dihiaskan di atasnya.

Mie rebusan, telah dituang dalam mangkuk, dan telah diberi lauk ayam, dan gorengan crispy. Ditambahkan nori rumput laut, telur setengah matang, sawi daging rebus. Dan siap dihidangkan[10][14].

Proses yang telah dijelaskan tersebut, direkam dengan baik, kemudian disusun menjadi video tutorial pembelajaran. Video tutorial/ pembelajaran diserahkan kepada operator pondok dan manajemen pondok, untuk digunakan belajar siswa, dengan menonton video. 


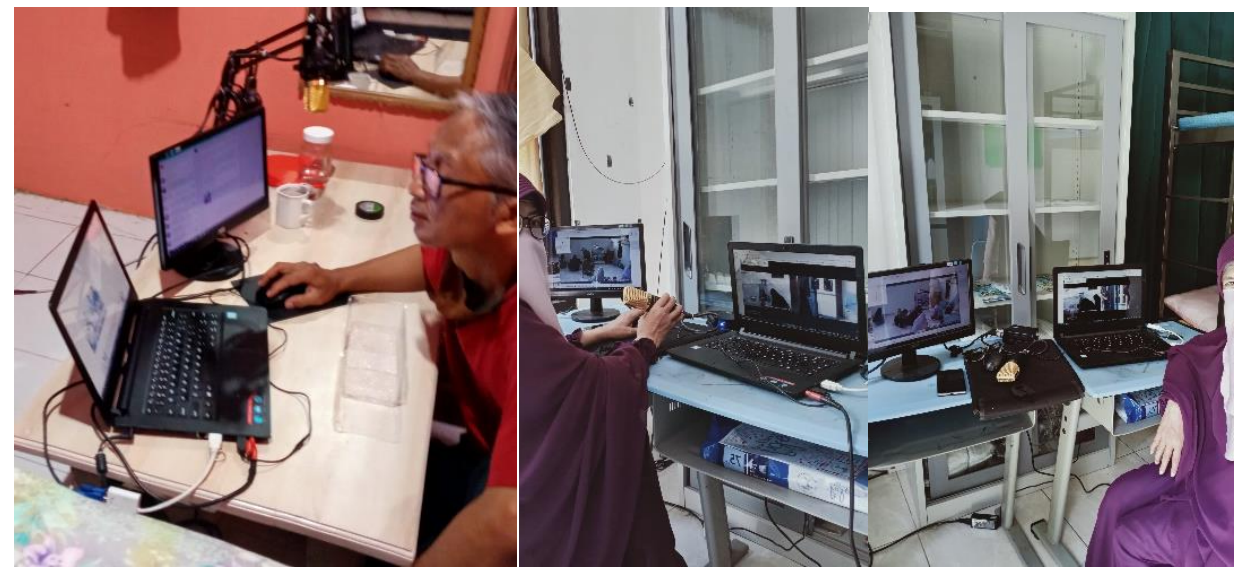

Gambar 5. Suasana persiapan dan pelaksanaan daring

Pembelajaran daring dilaksanakan pengajar dengan pendampingan oleh anggota pelaksana program pengabdian. Digunakan laptop, microphon, power amplifier, extended monitor. Tempat di ruang guru, yang terpisah dari ustadz/pengajar lainnya. Jaringan wifi disediakan pondok.

Pada saat pelaksanaan daring, pengajar berada di ruang berbeda dengan santri. Di ruang masak santri, dipasang IP Camera merk ELVIZ, dimana kamera dapat dikendalikan arah menghadapnya, naik/ turun/ kiri/ kanan/ jauh/ dekat.

Di ruang tersebut juga dipasang laptop, untuk komunikasi pembelajaran. Santri dapat menunjukkan melalui kamera laptop, dan atau IP Camera. Di ruang pembelajaran, praktis terdapat 2 kamera. Yaitu kamera laptop dan IP Camera.

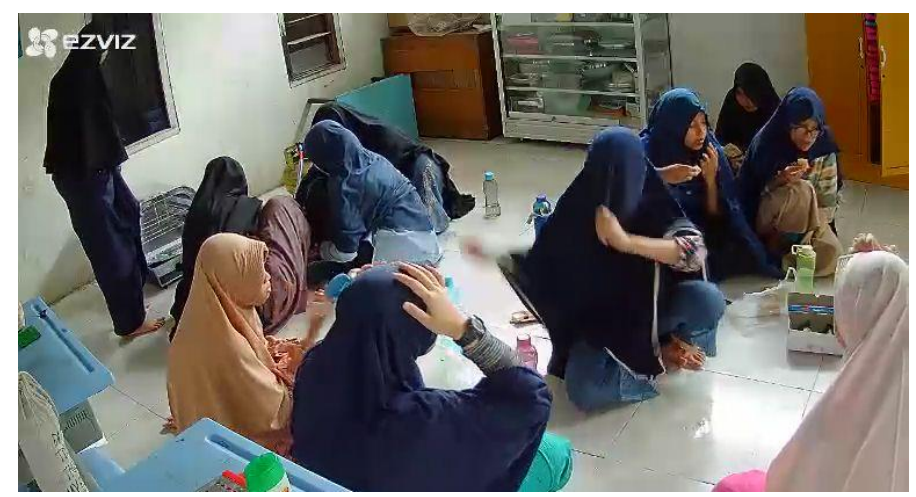

Gambar 6. Suasana persiapan dan pelaksanaan daring di ruang siswa/ santri.

Selesai acara memasak, ruangan praktek kembali dibersihkan, dan siapa dipergunakan untuk pelajaran berikutnya. Kegiatan pengabdian ini menghasilkan video tutorial memasak. Pada laporan ini video tersebut di extract menjadi frame frame gambar agar bisa dilaporkan secara tertulis.

Bahan ajar yang lain adalah tentang memasak cheese muffin dan choco muffin. Muffin adalah kue eropa yang terbuat dari bahan dasar margarin /butter, gula pasir, telur, tepung terigu, coklat bubuk, baking powder, susu cair, Choco chip/keju. Jendela jajanan Eropa yang lazim sebagai "pengganjal perut", atau cepat saji praktis[18]-[20]. Sering digunakan untuk sarapan, bekal sekolah, karena ringkas namun berkalori tinggi. Banyak tersedia resep muffin di internet, karenanya harus bijak memilih, atau lebih baik memodifikasinya sesuai selera atau kebutuhan. Kalorinya yang tinggi, gula yang tinggi mesti berhati hati bagi penderita diabetes[21].

Video pertama adalah Tutorial membuat Ayam Asam Manis. Video ini di ekstract menggunakan Free Video to JPG converter, menjadi 200 frame. Frame tersebut ditampilkan dalam windows explorer, dalam bentuk extra large icon. Icon icon tersebut kemudian di- screen-capture dan 
Pendampingan Pembelajaran Ketrampilan Secara Daring di Pondok Pesantren

Tarbiyatul Iman Malang

ditempelkan pada laporan ini. Terdapat 5 konten memasak yang dilaporkan pada kegiatan ini yaitu: 1) Mie ala Jepang 2) Ayam asam manis, 3) Cheese Muffin, 4) Choco Muffin.
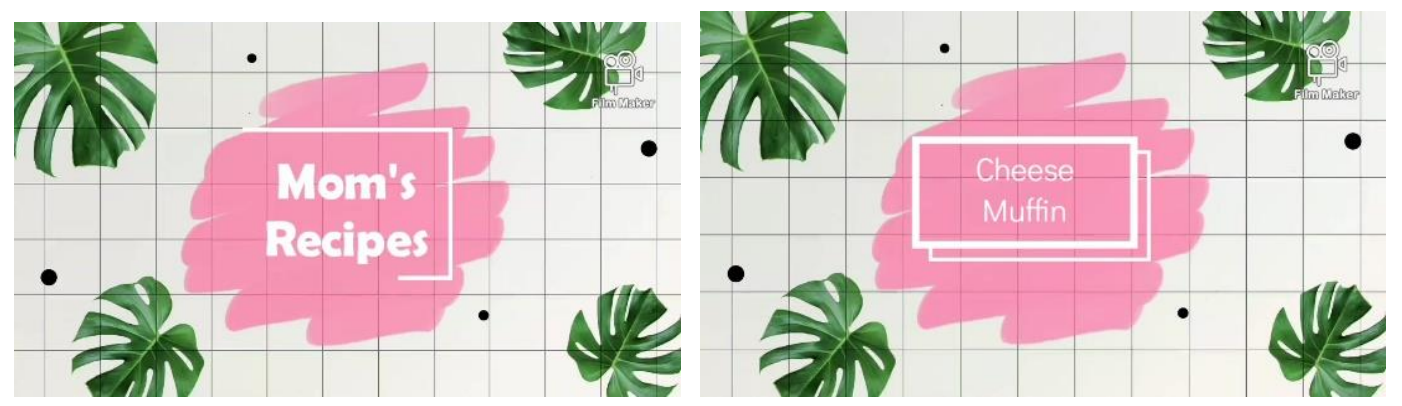

Gambar 7. Tampilan awalan video tutorial memasak cheese muffin
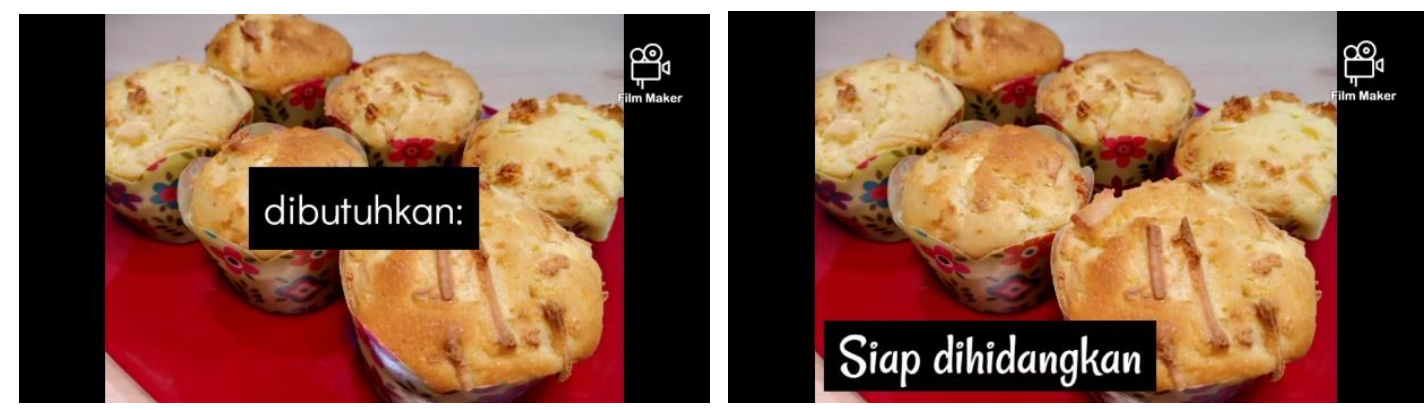

Gambar 8. Tampilan video tutorial memasak cheese muffin.

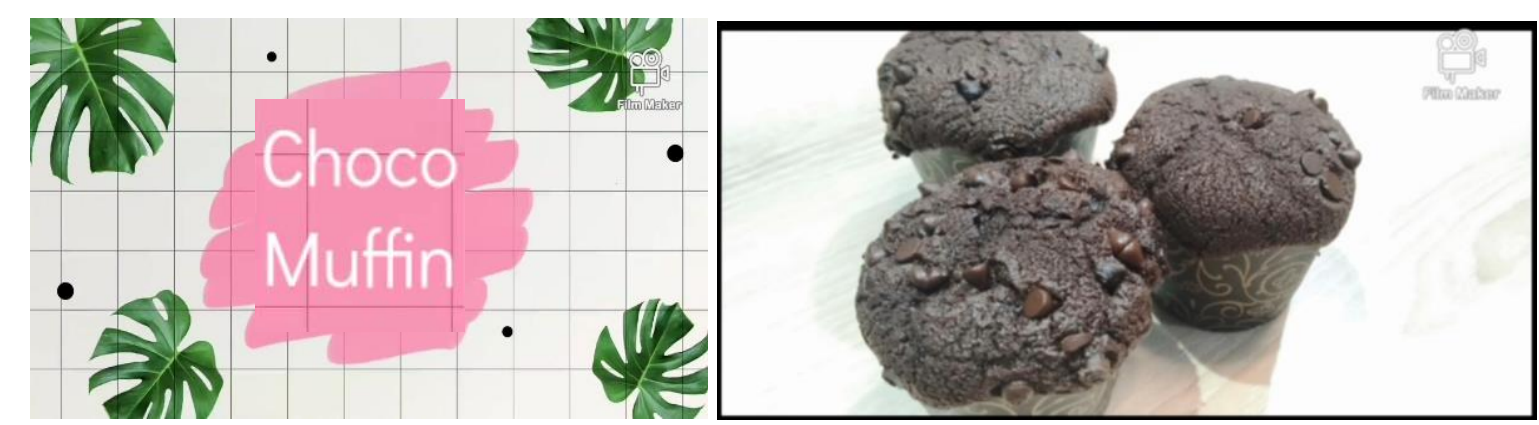

Gambar 9. Tampilan video tutorial memasak choco muffin.

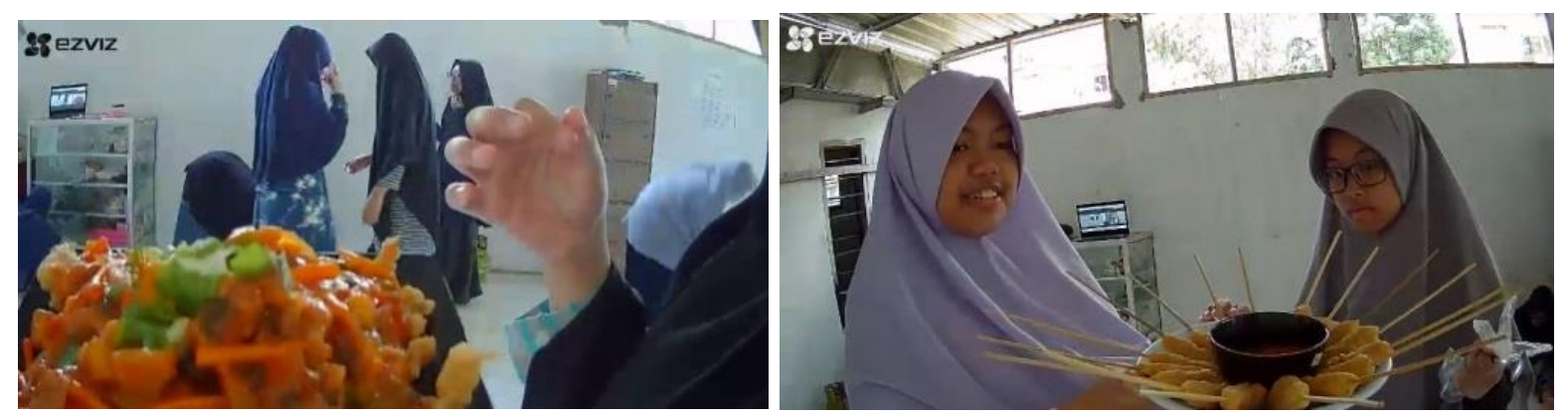

Gambar 10. Tampilan monitor IP kamera

Praktek memasak dilaksanakan di kelas memasak, dimana peralatan disediakan secara portable. Digelar saat dibutuhkan di rapikan masuk almari setelah selesai praktek. Pembelajaran dapat dilaksanakan dengan baik. Seluruh sudut ruangan dapat dipantau menggunakan IP camera sehingga memaksimalkan pemantauan terhadap siswa. Dengan cara ini siwa melaksanakan dengan baik tugas 
tugas yang diberikan. Komunikasi dilakukan menggunakan laptop, IP camera dan smartphone, sekaligus, dengan maksud meminimalkan kejadian terputusnya komunikasi.

Dari sisi siswi/santriwati, konten masakan yang dipilih, adalah menarik, terlihat dari antusiasme para santri mengikuti kegiatan praktek ini. Komunikasi yang lancar memudahkan para santri jika memerlukan arahan dari pengajar. Masakan yang memang populer/ digemari menjadi daya tarik tersendiri, sehingga santri tidak perlu dipaksa dalam mengikuti kelas.

Dari sisi ustadzah pengajar, pengabdian pada masyarakat ini menginspirasi bagaimana pemilihan menu, bagaimana melaksanakan daring praktek memasak dilaksanakan seakan luring. Mengendalikan, memandu memberi arahan kepada santri yang sedang memasak juga lebih mudah. Evaluasi pembelajarannya juga mudah.

Dari sisi lembaga, terlaksananya pembelajaran praktek ini menjadi solusi pada situasi pandemi. Pembelajaran dapat dilaksanakan dengan baik. Evaluasi capaian pembelajaran dengan cara daring sebagaimana sebagai hasil kegiatan pengabdian pada masyarakat ini adalah 80 hingga 85 . Nilai hasil pembelajaran daring ini semisal dengan pada saat pembelajaran luring yaitu antara 80 hingga 86 . Pada skala nilai A,B,C,D,E, nilai hasil pembelajaran adalah A, baik pada saat daring maupun luring yang dijelaskan pada gambar 11. Hal ini berarti kegiatan pengabdian pada masyarakat ini berhasil mempertahankan prestasi santri, sehingga tidak berdampak pandemi covid-19. Ini menjadi salah satu kelebihan belajar daring yaitu mendorong kemandirian siswa[22].

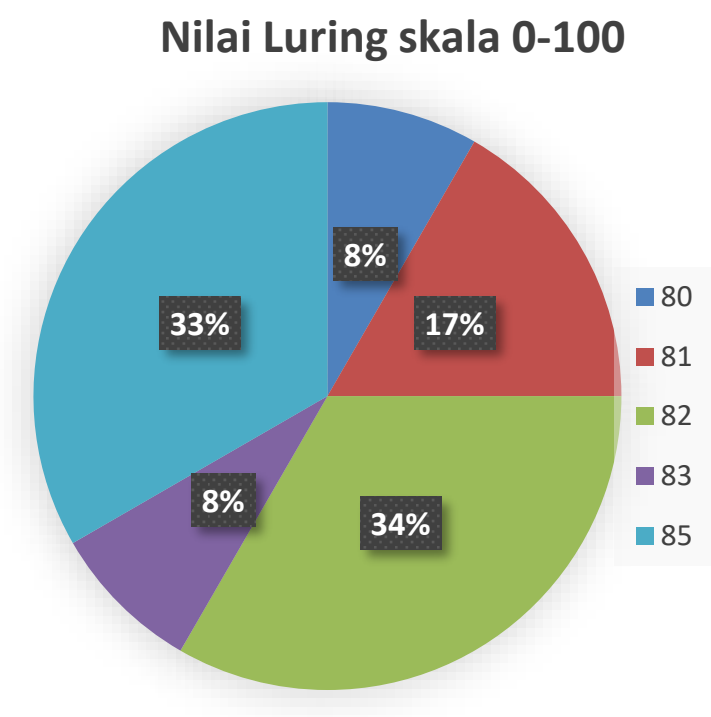

\section{Nilai Daring skala 0-100}

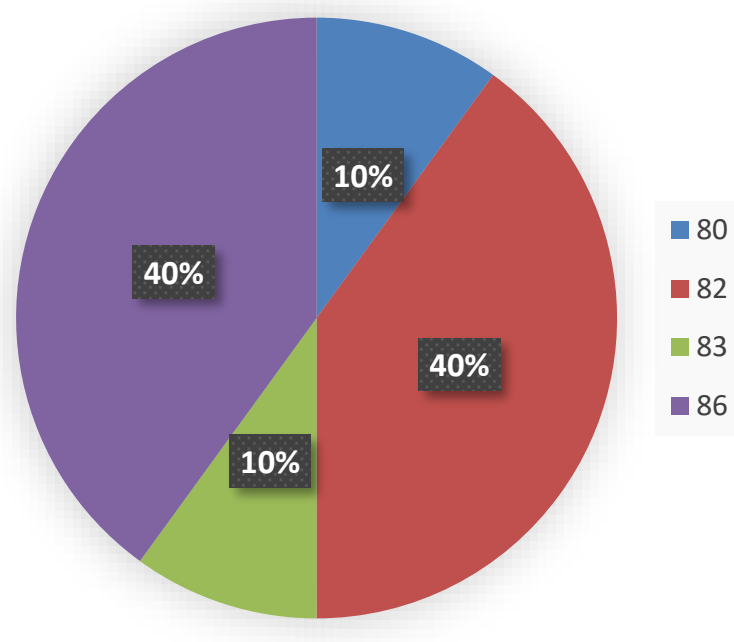

Gambar 11. Nilai luring dan daring

\section{SIMPULAN}

Dengan berakhirnya pendampingan pembelajaran daring di PPTI ini dapat disimpulkan bahwa: Pengajar telah menguasai teknologi, dan peralatan pembelajaran secara daring. Penguasaan alat dan teknologi ini akan menunjang pelaksanaan berikutnya secara mandiri. Pengajar juga memiliki kemampuan dalam membuat video tutorial memasak, dimana keterampilan dapat digunakan mensosialisasikan program program pondok. Tentu saja pada pengabdian ini telah dihasilkan video tutorial memasak, sebagaimana disebutkan dalam pembahasan. IP camera juga terbukti sangat membantu,dan mudah pengoperasiannya. Terlaksananya kelas praktek dimana santri bersama berada dalam kelas praktek. Terlaksananya pengajaran daring dimana pengajar berada di ruang guru mengajar secara daring. Kegiatan pengabdian pada masyarakat ini berhasil mempertahankan prestasi santri, sehingga tidak terdampak pandemi covid-19. 
Pendampingan Pembelajaran Ketrampilan Secara Daring di Pondok Pesantren

Tarbiyatul Iman Malang

\section{UCAPAN TERIMA KASIH}

Ucapan terima kasih kami sampaikan kepada Universitas Muhammadiyah Malang yang telah membiayai pengabdian pada masyarakat ini, melalui program hibah Fakultas Teknik.

\section{DAFTAR PUSTAKA}

[1] M. Mundir, "The portrait of learning media development of social media based in Islamic boarding school in the pandemic: study on kiai online reciting and santri social media literation in constructing negative contents in the virtual world," portrait Learn. media Dev. Soc. media based Islam. Board. Sch. pandemic study kiai online reciting santri Soc. media Lit. Constr. Negat. contents virtual world, 2020.

[2] A. Bacher-Hicks, J. Goodman, and C. Mulhern, "Inequality in household adaptation to schooling shocks: Covid-induced online learning engagement in real time," J. Public Econ., vol. 193, p. 104345, 2021, doi: 10.1016/j.jpubeco.2020.104345.

[3] L. J. Hunter, K. L. Bierman, and C. M. Hall, "Assessing Noncognitive Aspects of School Readiness: The Predictive Validity of Brief Teacher Rating Scales of Social-Emotional Competence and Approaches to Learning," Early Educ. Dev., vol. 29, no. 8, pp. 1081-1094, 2018, doi: 10.1080/10409289.2018.1495472.

[4] R. Rayuwati, "How educational technology innovates distance learning during pandemic crisis in remote areas in Indonesia?," Int. Res. J. Manag. IT Soc. Sci., vol. 7, no. 6, pp. 161-166, 2020, doi: 10.21744/irjmis.v7n6.1032.

[5] Rasmitadila et al., "The perceptions of primary school teachers of online learning during the covid-19 pandemic period: A case study in Indonesia," J. Ethn. Cult. Stud., vol. 7, no. 2, pp. 90-109, 2020, doi: 10.29333/ejecs/388.

[6] S. T. Joanis, "Family Meal Planning under COVID-19 Scarcity Constraints: A Linear Programming Approach," J. Food Nutr. Res., vol. 8, no. 9, pp. 484-495, 2020, doi: 10.12691/jfnr-8-9-5.

[7] H. P. Siregar, S. A. Putra, A. Taufan, and Y. R. Kurniawan, "Studi eksperimental prototip 1 mesin ekstruder mie jagung," Mekanika, vol. 12, no. 1, pp. 39-43, 2013.

[8] X. S.Mujumdard, "4D printing: Recent advances and proposals in the food sector," Trends Food Sci. Technol., vol. 110, pp. 349-363, 2021.

[9] A. Derossi, R. Caporizzi, I. Ricci, and C. Severini, Critical variables in $3 D$ food printing. Elsevier Inc., 2018.

[10] M. Yuasa, Y. Tagawa, and M. Tominaga, "The texture and preference of "mentsuyu (Japanese noodle soup base) caviar' prepared from sodium alginate and calcium lactate," Int. J. Gastron. Food Sci., vol. 18, no. April, p. 100178, 2019, doi: 10.1016/j.ijgfs.2019.100178.

[11] R. Tajima et al., "Association between rice, bread, and noodle intake and the prevalence of non-alcoholic fatty liver disease in Japanese middle-aged men and women," Clin. Nutr., vol. 36, no. 6, pp. 1601-1608, 2017, doi: 10.1016/j.clnu.2016.09.034.

[12] S. S. Cha and X. W. Wang, "A Cross-National Study on Selection Attributes of Instant Noodle between China and Korea," J. Food Prod. Mark., vol. 26, no. 1, pp. 1-16, 2020, doi: 10.1080/10454446.2019.1711483.

[13] C. K. Kamalakanth, "Development of ready-to-eat extruded fish based noodles in semi-rigid containers"," pp. 1-195, 2015.

[14] S. Kim, E. Park, and D. Lamb, "Extraordinary or ordinary? Food tourism motivations of Japanese domestic noodle tourists," Tour. Manag. Perspect., vol. 29, no. January, pp. 176-186, 2019, doi: 10.1016/j.tmp.2019.01.001.

[15] G. Petersen, "Washoku Down Under by," 2017.

[16] Y. Lusiana, P. M. Laksono, and T. Hariri, "Self-Styling, Popular Culture, and the Construction of Global-Local Identity among Japanese Food Lovers in Purwokerto," I-Pop Int. J. Indones. Pop. Cult. Commun., vol. 1, no. 1, pp. 21-40, 2020, doi: 10.36782/i-pop.v1i1.33.

[17] G. Watson, "American Versus Japanese Quality: Let the Noodle be the Noodle," J. Qual. Particip., vol. 42, no. 1, p. 32, 2019. 
[18] A. R. Farris, M. Roy, E. L. Serrano, and S. Misyak, "Impact of Breakfast in the Classroom on Participation and Food Waste," J. Nutr. Educ. Behav., vol. 51, no. 7, pp. 893-898, 2019, doi: 10.1016/j.jneb.2019.04.015.

[19] J. Hanson, J. Elmore, and M. Swaney-Stueve, "Food trying and liking related to grade level and meal participation," Int. J. Environ. Res. Public Health, vol. 17, no. 16, pp. 1-11, 2020, doi: 10.3390/ijerph17165641.

[20] L. M. Panek-Shirley, C. DeNysschen, E. O’Brien, and J. L. Temple, “Caffeine Transiently Affects Food Intake at Breakfast," J. Acad. Nutr. Diet., vol. 118, no. 10, pp. 1832-1843, 2018, doi: 10.1016/j.jand.2018.05.015.

[21] M. L. Stewart and J. P. Zimmer, "Postprandial glucose and insulin response to a high-fiber muffin top containing resistant starch type 4 in healthy adults: a double-blind, randomized, controlled trial," Nutrition, vol. 53, pp. 59-63, 2018, doi: 10.1016/j.nut.2018.01.002.

[22] D. R. Hidayat, A. Rohaya, F. Nadine, and H. Ramadhan, "Kemandirian Belajar Peserta Didik Dalam Pembelajaran Daring Pada Masa Pandemi Covid -19," Perspekt. Ilmu Pendidik., vol. 34, no. 2, pp. 147-154, 2020, doi: 10.21009/pip.342.9. 